\title{
Lung Sound Analysis and the Respiratory Cycle Dependence of Impulse Oscillometry in Asthma Patients
}

\author{
Terufumi Shimoda ${ }^{1}$, Yasushi Obase ${ }^{2}$, Yukio Nagasaka ${ }^{3}$, \\ Reiko Kishikawa $^{1}$ and Tomoaki Iwanaga ${ }^{1}$
}

\begin{abstract}
:
Objective A lung sound analysis (LSA) is useful for detecting airway inflammation and obstruction in patients with asthma. To elucidate the mechanism of LSA, we investigated the relationship between the exhalation-to-inhalation sound pressure ratio in the low frequency range between 100 and $195 \mathrm{~Hz}$ (E/I LF) and the respiratory cycle dependence of impulse oscillometry (IOS) parameters.

Methods Asthma patients underwent IOS [resistance of the respiratory system at $5 \mathrm{~Hz}$ (R5) and $20 \mathrm{~Hz}$ (R20), the reactance area (AX), resonant frequency of reactance (Fres), and reactance of the respiratory system at $5 \mathrm{~Hz}$ (X5)], spirography, and an LSA. The correlation between the LSA-derived E/I LF values and the respiratory cycle dependence of the IOS parameters was analyzed.

Patients Thirty-four patients with mild to moderate bronchial asthma, who had not received oral or inhaled corticosteroids and who had no episodes of rumbling or wheezing were examined.

Results The E/I LF value was significantly correlated with the differences of the R5 and R5-R20 values between exhalation and inhalation $(\mathrm{p}=0.035$ and $\mathrm{p}=0.050)$ in a multivariate analysis.

Conclusion E/I LF appears to be an index that expresses the respiratory cycle dependence of asthma as well as IOS.
\end{abstract}

Key words: bronchial asthma, impulse oscillometry, lung sound analysis, respiratory cycle dependence, respiratory function

(Intern Med 58: 47-52, 2019)

(DOI: 10.2169/internalmedicine.8226-16)

\section{Introduction}

During auscultation of healthy individuals, vesicular breath sounds are small and low at the lung bases that are furthest from the large airways. Expiration occurs far from where the sounds are generated and this sound is audible, even during expiration, when a lesion is present in the airway (1). The changes in lung and/or airway conditions, may cause some subtle changes in the breath sounds auscultated at the lung bases. In our previous study, we used a computer-aided lung sound analysis (LSA) to investigate slight changes in breath sounds that are inaudible to the ear in patients with bronchial asthma. The patients were found to have higher exhalation-to-inhalation sound pressure ratios in the low frequency range between 100 and $195 \mathrm{~Hz}$ (E/I LF) (2). We have also reported that E/I LF can be easily obtained without any harm, which is useful for predicting a worsening of asthma (3).

Impulse oscillometry (IOS) is a method that is applied from the forced oscillation technique and which measures respiratory resistance and respiratory reactance using impulse signals containing low frequency (between 0 and 100 $\mathrm{Hz}$ ) components. A correlation between the resistance of the respiratory system at $5 \mathrm{~Hz}$ (R5) measured by IOS and the forced expiratory volume in one second $\left(\mathrm{FEV}_{1.0}\right)$ in bronchial asthma patients has been reported (4). IOS measurements, in addition to the spirometric determination of the maximal expiratory flow at $50 \%$ and $25 \%$ of FVC $\left(\% \dot{V}_{50}\right.$ and $\% \dot{V}_{25}$ ), will not only enable the further differentiation of

${ }^{1}$ Clinical Research Center, Fukuoka National Hospital, Japan, ${ }^{2}$ Department of Respiratory Medicine, Nagasaki University Graduate School of Biomedical Sciences, Japan and ${ }^{3}$ Kyoto Respiratory Center, Otowa Hospital, Japan

Received: September 6, 2016; Accepted: May 1, 2018; Advance Publication by J-STAGE: August 24, 2018

Correspondence to Dr. Terufumi Shimoda, t-shimoda@mfukuoka2.hosp.go.jp 
peripheral airway lesions but also serve as an index for monitoring the therapeutic course (5-7). This method has advantages in that it does not require forced exhalation and it can be applied quickly during quiet breathing, even for those of advanced age and/or an impaired lung function. A higher shift in respiratory system resistance or a lower shift in respiratory system reactance during exhalation in comparison to during inhalation, which is referred to as respiratory cycle dependence, was found in patients with severe bronchial asthma $(8,9)$.

We previously reported that E/I LF as well as reactance of the respiratory system at $5 \mathrm{~Hz}$ (X5) can be an indicator of central and peripheral airway obstruction in bronchial asthma patients (10); however, in that study we did not consider the respiratory cycle dependence of the IOS factors. In this study, we investigated the relationships between the E/I LF and respiratory cycle dependence of IOS in nonsmoking steroid-naive interictal patients with mild to moderate bronchial asthma and no rumbling or wheezing.

\section{Materials and Methods}

\section{Subjects}

In the present study, 34 patients with mild to moderate bronchial asthma were assessed. The ages of the patients ranged from 20 to 65 years (average: 43.1 years); none of the patients were smoking at the time of the study (some had a past history of smoking). All patients fulfilled the Global Initiative for Asthma (GINA) criteria (11), and had a history of asthmatic symptoms, including recurrent cough, wheezing, or dyspnea, as well as positive airway hyperresponsiveness. The spirometry data, chest $\mathrm{X}$ ray and highresolution $\mathrm{CT}$ (as needed in patients) findings showed no evidence of chronic obstructive pulmonary disease (COPD) in any patient. All patients retained a normal diffusion capacity. None of the patients had used inhaled or oral corticosteroids in the past. Anti-asthma drugs, including bronchodilators, were discontinued for at least 24 hours prior to this examination. Wheezing was not heard on auscultation in any patient.

The ethics committee of Fukuoka National Hospital approved the study protocol (protocol No.: 20-12), and all participants received verbal and written information about the study before they provided their informed consent.

\section{Forced oscillation technique}

The IOS MasterScreen device (Erich Jaeger, Wurzburg, Germany) consists of a loudspeaker as a pulse generator to send pressure impulses to the respiratory system. The system is calibrated through a single volume of air $(3 \mathrm{~L})$ at different flow rates and with a reference resistance device $(0.2$ $\mathrm{kPa} / \mathrm{L}$ per second). The patients used nose clips and a disposable mouthpiece (Fit mouthpiece, Chest, Tokyo, Japan); patients supported their cheeks with their hands to decrease the shunt compliance. In this study, the mean respiratory re- sistance values (at inhalation, at exhalation and whole breath) were calculated over a measurement period of 30 seconds in a frequency range of 5-35 HZ. The impedance (Z), representing a complex airway resistance, which includes two components, the real resistance $(\mathrm{R})$ and the imaginary reactance $(\mathrm{X})$ were determined $(10,12)$.

\section{Lung sound analysis (LSA)}

Lung sounds were recorded using a hand-held microphone over the left lung base (where we could most clearly recognize the alveolar respiratory sound) for $\geq 30$ seconds $(2,13)$. The recording system consisted of an electrostethoscope containing a wide-range audio sensor that adhered to the inside of a diaphragm (Bio-Sound Sensor BSS01; Kenzmedico, Saitama, Japan), a signal processing system, and a personal computer. The sensor had a band-pass filter range of 40-2,500 $\mathrm{Hz}$ and good sound-collecting ability in the 40-2,000 Hz range. The recorded sound was analyzed using a sound spectrometer (LSA-2008; Kenzmedico, Saitama, Japan). Single-breath cycle data with lower noise levels were selected visually and analyzed to determine the mean inhalation sound pressure level and the mean exhalation sound pressure in the $100-195-\mathrm{Hz}$ frequency band. We defined the frequency range of $100-195 \mathrm{~Hz}$ as LF and determined the inspiration sound power, expiration sound power, and inspiration-to-expiration sound power ratio in the lowfrequency range (E LF, I LF and E/I LF). The E/I LF data were converted from logarithmic values $(\mathrm{dBm})(2)$. The sound recording was performed in a quiet room-but not a soundproof booth-in the outpatient department. The patients took a deep breath during the breath sound recording.

\section{Measurement of the flow-volume curves}

The lung function was measured using a spirometer (Chest Graph HI-701, Chest M.I., Tokyo, Japan). The results are expressed as the percentage of the predicted values based on the relevant reference standards (14).

\section{Measurement of airway hyperresponsiveness to ace- tylcholine}

The challenge test was performed using the standard method. The subjects first inhaled isotonic saline for $2 \mathrm{~min}$ utes from a hand-held nebulizer (PARI BOY 038; PARI $\mathrm{GmbH}$, Starnberg, Germany). They then inhaled Ach at concentrations that progressively doubled from 39 to 20,000 $\mathrm{mcg} / \mathrm{mL}$. The test was continued until the FEV1.0 decreased by $>20 \%$. Bronchial hyperresponsiveness was expressed as the provocative concentration of acetylcholine causing a $20 \%$ reduction in $\mathrm{FEV}_{1}\left(\mathrm{PC}_{20}\right)$. Subjects with a $\mathrm{PC}_{20}$ value of $<8,000 \mathrm{mcg} / \mathrm{mL}$ were considered to have a positive bronchial hyperresponsiveness (15).

\section{Statistical analysis}

The IOS parameters during inhalation and exhalation were compared using $t$-tests. The correlation between E/I LF and clinical factors or IOS parameters [inhalation, exhalation, and the differences between exhalation and inhalation 
$(\Delta)$ ] were performed using Spearman's rank test. A stepwise method was used for the multivariate analysis of the correlation between E/I LF and clinical factors or IOS parameters. With regard to explanatory variables, sex and $\mathrm{FEV}_{1.0, \text { \% }}$ predicted were selected as independent factors without confounders and the difference in the resistance of the respiratory system at $5 \mathrm{~Hz}$ between inhalation and exhalation $(\Delta \mathrm{R} 5), \Delta[\mathrm{R} 5-$ resistance of the respiratory system at $20 \mathrm{~Hz}$ (R20)], and the difference in the resonant frequency of reactance between inhalation and exhalation ( $\Delta$ Fres) were repeatedly selected as IOS parameters. These statistical analyses were conducted using the JMP Pro software program (version 11, SAS Institute, Cary, USA) and the $\mathrm{R}$ software program (version 3.1.2).

\section{Results}

\section{Patient characteristics}

The mean age of the patients was 43.1 years and the study population had a female predominance (male, $n=4$; female, $n=30$ ). None of the patients were current smokers; 13 had a history of smoking with a mean life-time tobacco use of 5.56 pack-years. The type of asthma was atopic in 18 pa-

Table 1. Patient Characteristics.

\begin{tabular}{|c|c|}
\hline & Mean $(95 \% \mathrm{CI})$ \\
\hline Age (yr) & $43.1(38.4-47.9)$ \\
\hline BMI & $22.6(21.6-23.7)$ \\
\hline male/female & $4 / 30$ \\
\hline Asthma duration (yr) & $8.0(4.2-11.8)$ \\
\hline Atopic/non-atopic & $18 / 16$ \\
\hline Smoking non/ex/ current & $21 / 13 / 0$ \\
\hline Smoking amount (pack-years) & $5.56(1.80-9.32)$ \\
\hline Severity mild/moderate & $14 / 20$ \\
\hline $\log \operatorname{IgE}$ & $1.99(1.73-2.25)$ \\
\hline $\mathrm{PC}_{20}(\mathrm{mcg} / \mathrm{mL})$ & $1,470(940-2,000)$ \\
\hline $\log \mathrm{PC}_{20}$ & $2.91(2.73-3.09)$ \\
\hline $\mathrm{FEV}_{1.0} / \mathrm{FVC} \%(\%)$ & $78.4(75.1-81.7)$ \\
\hline $\mathrm{FEV}_{1.0, \% \text { predicted. }}(\%)$ & $95.4(89.1-101.7)$ \\
\hline$\dot{\mathrm{V}}_{50, \% \text { predicted. }}(\%)$ & $72.5(63.2-81.8)$ \\
\hline$\dot{\mathrm{V}}_{25, \% \text { predicted. }}(\%)$ & $53.8(44.1-63.6)$ \\
\hline $\mathrm{E} / \mathrm{I} \mathrm{LF}$ & $0.35(0.28-0.41)$ \\
\hline
\end{tabular}

tients and non-atopic in 16 patients. The study population had a mean $\log \mathrm{PC}_{20}$ of 2.91 , a mean $\mathrm{FEV}_{1.0, \text { \% }}$ predicted. of $95.4 \%$, and a mean $\dot{V}_{50, \% \text { predicted }}$ of $72.5 \%$. The patients had a mean E/ I LF of 0.35 (Table 1).

\section{Comparison of the inhalation and exhalation data from IOS}

The IOS R5, R20, and (R5-R20) values were significantly higher during exhalation than inhalation, whereas the reactance components [reactance of the respiratory system at 5 $\mathrm{Hz}(\mathrm{X} 5)$, reactance area (AX) and Fres] did not differ to a statistically significant extent between exhalation and inhalation (Table 2).

The correlations between E/I LF and the clinical factors and IOS parameters during inhalation, exhalation, and the difference between exhalationinhalation $(\Delta)$

With regard to the single correlations, the E/I LF was correlated with the disease period, $\mathrm{FEV}_{1.0}$ \% predicted, $\dot{\mathrm{V}}_{50}$, \%predicted, $\log \mathrm{PC}_{20}$, and $\log \mathrm{IgE}$. The $\mathrm{E} / \mathrm{I} \mathrm{LF}$ was significantly correlated with both the exhalation and inhalation data for R5 and R20. However, the E/I LF only showed a significant with the exhalation data (and not the inhalation data) for R5-R20, X5, AX, and Fres. The E/I LF was significantly correlated with $\Delta \mathrm{R} 5, \Delta(\mathrm{R} 5-\mathrm{R} 20)$ and $\Delta$ Fres (Table $3 \mathrm{a})$.

In a stepwise multiple regression analysis to detect significant relationships, E/I LF, sex and $\mathrm{FEV}_{1.0 \text {, \%predicted (inde- }}$ pendent factors without an interrelationship) were included as clinical explanatory variables and each IOS parameter was added in a step-wise manner (Table 3b). E/I LF was higher in male patients $(\mathrm{p}<0.05)$, patients with lower $\mathrm{FEV}_{1.0 \text {, \%predicted }}(\mathrm{p}<0.0001)$ (among clinical factors), and patients with a higher $\Delta \mathrm{R} 5(\mathrm{p}=0.035)$ or higher $\Delta(\mathrm{R} 5-\mathrm{R} 20)$ value $(p=0.05)$ (among all analyzed IOS factors and differences in IOS factors between inhalation and exhalation).

\section{Discussion}

In the present study, we found E/I LF to correlate with sex and $\mathrm{FEV}_{1.0,}$ \%predicted, and $\Delta \mathrm{R} 5$ and $\Delta(\mathrm{R} 5-\mathrm{R} 20)$, which may suggest that the E/I LF mechanism is related to not only airway constriction, but also to respiratory cycle dependence.

In bronchial asthma patients, the sounds detected by LSA

Table 2. Comparison of the Impulse Oscillometry Parameters between Inhalation and Exhalation.

\begin{tabular}{lccc}
\hline & Inhalation & Exhalation & $\mathrm{p}$ value \\
\hline resistance of the respiratory system at $5 \mathrm{~Hz}(\mathrm{R} 5)$ & $0.30(0.09)$ & $0.34(0.10)$ & 0.0003 \\
resistance of the respiratory system at $20 \mathrm{~Hz}(\mathrm{R} 20)$ & $0.26(0.08)$ & $0.30(0.08)$ & $<0.0001$ \\
R5-R20 & $0.03(0.03)$ & $0.05(0.04)$ & 0.049 \\
reactance of the respiratory system at $5 \mathrm{~Hz}$ & $-0.11(0.05)$ & $-0.11(-0.05)$ & 0.476 \\
reactance area & $0.34(0.22)$ & $0.38(0.30)$ & 0.297 \\
resonant frequency of reactance & $11.89(2.84)$ & $12.93(4.11)$ & 0.080 \\
\hline
\end{tabular}

Data are presented by mean (standard deviation). 
Table 3. Single Correlations (3a) and Multiple Regression Analysis (3b) of E/I LF with Clinical Factors and Impulse Oscillometry Parameters.

\begin{tabular}{|c|c|c|}
\hline \multicolumn{3}{|l|}{$3 a$} \\
\hline \multicolumn{3}{|c|}{ Single correlations } \\
\hline parameters & $\mathrm{r}$ & $\mathrm{p}$ value \\
\hline R5 In. & 0.36 & 0.035 \\
\hline R5 Ex. & 0.53 & 0.001 \\
\hline$\Delta \mathrm{R} 5$ & 0.48 & 0.004 \\
\hline R20 In. & 0.37 & 0.033 \\
\hline R20 Ex. & 0.4 & 0.018 \\
\hline$\Delta \mathrm{R} 20$ & 0.28 & 0.10 \\
\hline (R5-R20) In. & 0.15 & 0.40 \\
\hline (R5-R20) Ex. & 0.48 & 0.004 \\
\hline$\Delta(\mathrm{R} 5-\mathrm{R} 20)$ & 0.36 & 0.035 \\
\hline X5 In. & -0.28 & 0.11 \\
\hline X5 Ex. & -0.49 & 0.004 \\
\hline$\Delta \mathrm{X} 5$ & -0.12 & 0.51 \\
\hline AX In. & 0.28 & 0.10 \\
\hline AX Ex. & 0.47 & 0.005 \\
\hline$\Delta \mathrm{AX}$ & 0.22 & 0.21 \\
\hline Fres In. & 0.31 & 0.08 \\
\hline Fres Ex. & 0.47 & 0.005 \\
\hline$\Delta$ Fres & 0.35 & 0.04 \\
\hline age & -0.24 & 0.17 \\
\hline Disease period & 0.48 & 0.004 \\
\hline Smoking history & 0.28 & 0.12 \\
\hline $\mathrm{FEV}_{1.0,} \%$ predicted. $(\%)$ & -0.53 & 0.001 \\
\hline$\dot{\mathrm{V}}_{50, \% \text { predicted. }}(\%)$ & -0.36 & 0.036 \\
\hline$\dot{\mathrm{V}}_{25, \% \text { predicted. }}(\%)$ & -0.31 & 0.078 \\
\hline $\log \mathrm{PC}_{20}$ & -0.43 & 0.001 \\
\hline $\log \operatorname{IgE}$ & 0.36 & 0.036 \\
\hline
\end{tabular}

\begin{tabular}{|c|c|c|c|c|c|}
\hline & $\begin{array}{l}\text { Partial regression } \\
\text { coefficient }\end{array}$ & $\begin{array}{l}\text { Standardised partial } \\
\text { regression coefficient }(\beta)\end{array}$ & SE & $\mathrm{t}$ value & $\mathrm{p}$ value \\
\hline \multicolumn{6}{|l|}{$\begin{array}{l}\text { Adjusted } \\
\mathrm{R}^{\wedge} 2=0.528\end{array}$} \\
\hline $\operatorname{SEX}[F]$ & -0.112 & -0.396 & 0.034 & -3.29 & 0.003 \\
\hline $\mathrm{FEV}_{1}, \%$ predicted & -0.006 & -0.560 & 0.001 & -4.67 & $<0.0001$ \\
\hline$\Delta \mathrm{R} 5$ & 0.813 & 0.266 & 0.368 & 2.21 & 0.035 \\
\hline \multicolumn{6}{|l|}{$\begin{array}{l}\text { Adjusted } \\
\mathrm{R}^{\wedge} 2=0.518\end{array}$} \\
\hline SEX $[F]$ & -0.097 & -0.344 & 0.036 & -2.7 & 0.011 \\
\hline $\mathrm{FEV}_{1}, \%$ predicted & -0.006 & -0.556 & 0.001 & -4.58 & $<0.0001$ \\
\hline$\Delta \mathrm{R} 5-\mathrm{R} 20$ & 1.432 & 0.260 & 0.702 & 2.04 & 0.050 \\
\hline \multicolumn{6}{|l|}{$\begin{array}{l}\text { Adjusted } \\
\mathrm{R}^{\wedge} 2=0.495\end{array}$} \\
\hline $\operatorname{SEX}[F]$ & -0.112 & -0.398 & 0.035 & -3.19 & 0.003 \\
\hline $\mathrm{FEV}_{1}, \%$ predicted & -0.006 & -0.553 & 0.001 & -4.45 & 0.0001 \\
\hline$\Delta$ Fres & 0.011 & 0.203 & 0.007 & 1.61 & 0.117 \\
\hline
\end{tabular}

E/I LF: expiration-to-inspiration sound power ratio in the low-frequency range, R5: resistance of the respiratory system at $5 \mathrm{~Hz}$, In: inhalation, Ex: exhalation, $\Delta$ : the differences between exhalation and inhalation, R20: resistance of the respiratory system at $20 \mathrm{~Hz}, \mathrm{R} 5$ - R20: difference between R5 and R20, X5: reactance of the respiratory system at $5 \mathrm{~Hz}, \mathrm{AX}$ : reactance area, Fres: resonant frequency of reactance, $\mathrm{FEV}_{1.0}$ : forced expiratory volume in one second, $\dot{\mathrm{V}}_{50}$ and $\dot{\mathrm{V}}_{25}$ : maximal expiratory flows at $50 \%$ and $25 \%$ of FVC, respectively, PC20: provocative concentration of acetylcholine causing a $20 \%$ decrease in the $\mathrm{FEV}_{1.0}$ 
during exhalation are usually stronger than those detected during inhalation (2). The amplitude of a sound wave is an index of the airflow rate, which may have a greater impact on lung sounds (16-18). We calculated the exhalation-toinhalation ratio and demonstrated that the E/I LF value can be used as an indicator of airway inflammation and obstruction in bronchial asthma $(2,10)$. We previously reported that E/I LF can be used similarly to X5 an indicator of the central and peripheral airway obstruction in bronchial asthma patients (10). X5 is reported as a parameter of peripheral capacitive reactance (7). A correlation between R5 (measured by IOS) and $\mathrm{FEV}_{1.0}$ in bronchial asthma patients has been reported (4) However, in these studies, the respiratory cycle dependence of IOS factors was not considered to explain the E/I LF mechanism. In this study, a multivariate analysis showed that E/I LF was correlated with $\Delta \mathrm{R} 5$ or $\Delta(\mathrm{R} 5-\mathrm{R} 20)$, which may suggest the E/I LF is a respiratory cycledependent factor and that E/I LF may reflect the more peripheral airway situation.

Patients with bronchial asthma and COPD demonstrate respiratory cycle dependence on IOS; the inhalation-toexhalation differences in the IOS reactance and resistance data of bronchial asthma and COPD patients differ from those of healthy individuals (19). The present study evaluated patients with bronchial asthma that was not complicated by COPD and found that among their IOS resistance components, their R5 values during exhalation were significantly higher than those during inhalation. However, female patients have lower E/I LF values; and Mori et al. demonstrated that patients with bronchial asthma had significant inhalation-to-exhalation differences in their R50, R20, R5R20, Fres and AX values but not their X5 values (20). The E/I LF was significantly correlated with R5 and R20 during both exhalation and inhalation and with R5-R20 and X5, $\mathrm{AX}$ and Fres (reactance components), which are indicators of peripheral airway lesions during exhalation alone. Bronchial asthma is characterized by chronic airway inflammation with airway epithelial exfoliation. It is a respiratory disease involving airway obstruction that exhibits more pronounced expiratory airflow restriction due to airway smooth muscle constriction, airway edema, elevated airway secretion, airway wall remodeling, and other factors than those observed in normal exhalation. Moreover, E/I LF was independently correlated with $\Delta \mathrm{R} 5$ and $\Delta(\mathrm{R} 5-\mathrm{R} 20)$, which may suggest the E/I LF reflects the respiratory cycle dependence of asthma. In this study, we hypothesize that the lower frequency of a smoking history in the male patients might have influenced the result. The independent negative relationship between FEV and E/I LF may suggest that the E/I LF is not only a respiratory cycle factor but that it also reflects the constriction of the airway.

This present study is associated with some limitations. First, the number of patients was small. We could not perform a multiple regression analysis with sufficient numbers of other factors, so we analyzed the relationships between E/ I LF and some of the clinical factors or IOS parameters without confounding factors. Second, there was no unified view about whether the IOS parameters could indicate peripheral airway stenosis.

In conclusion, E/I LF was independently correlated with the changes of R5 and R5-R20 between exhalation and inhalation on IOS. E/I LF may express the respiratory cycle dependence of asthma as well as IOS.

The authors state that they have no Conflict of Interest (COI).

\section{Acknowledgements}

I would like to thank Miss M. Oda and Miss K. Kojima for their valuable technical assistance and for performing the statistical analyses.

\section{References}

1. Nagasaka Y. Lung sounds in bronchial asthma. Allergol Int 61: 353-363, 2012.

2. Shimoda T, Nagasaka Y, Obase Y, Kishikawa R, Iwanaga T. Prediction of airway inflammation in patients with asymptomatic asthma by using lung sound analysis. J Allergy Clin Immunol Pract 2: 727-732, 2014.

3. Shimoda T, Obase Y, Nagasaka Y, Nakano H, Kishikawa R, Iwanaga T. Lung sound analysis can be an index of the control of bronchial asthma. Allergol Int 66: 64-69, 2017.

4. Nair A, Ward J, Lipworth BJ. Comparison of bronchodilator response in patients with asthma and healthy subjects using spirometry and oscillometry. Ann Allergy Asthma Immunol 107: 317$322,2011$.

5. Pisi R, Tzani P, Aiello M, et al. Small airway dysfunction by impulse oscillometry in asthmatic patients with normal forced expiratory volume in the 1st second values. Allergy Asthma Proc 34: e14-e20, 2013.

6. Larsen GL, Morgan W, Heldt GP, et al. Impulse oscillometry versus spirometry in a long-term study of controller therapy for pediatric asthma. J Allergy Clin Immunol 123: 861-867, 2009.

7. Shi Y, Aledia AS, Tatavoosian AV, Vijayalakshmi S, Galant SP, George SC. Relating small airways to asthma control by using impulse oscillometry in children. J Allergy Clin Immunol 129: 671678, 2012.

8. Paredi P, Goldman M, Alamen A, et al. Comparison of inspiratory and expiratory resistance and reactance in patients with asthma and chronic obstructive pulmonary disease. Thorax 65: 263-267, 2010.

9. Sugiyama A, Hattori N, Haruta Y, et al. Characteristics of inspiratory and expiratory reactance in interstitial lung disease. Respir Med 107: 875-882, 2013.

10. Shimoda T, Obase $Y$, Nagasaka $Y$, Kishikawa R, Mukae H, Iwanaga T. Peripheral bronchial obstruction evaluation in patients with asthma by lung sound analysis and impulse oscillometry. Allergol Int 66: 132-138, 2017.

11. Global Initiative for Asthma (GINA). Global strategy for asthma management and prevention. In: NHLBI/WHO Report, NIH Publication 02-3659. Bethesda National Institutes of Health, National Heart, Lung and Blood Institute, Bethesda, MD, 2006.

12. Smith HJ, Reinhold P, Goldman MD. Forced oscillation technique and impulse oscillometry. Lung Function Test 31: 72-105, 2005.

13. Jones A, Jones RD, Kwong K, Burns Y. Effect of positioning on recorded lung sound intensities in subjects without pulmonary dysfunction. Phys Ther 79: 682-690, 1999.

14. Standards for the diagnosis and care of patients with chronic obstructive pulmonary disease (COPD) and asthma. This official statement of the American Thoracic Society was adopted by the 
ATS Board of Directors, November 1986. Am Rev Respir Dis 136: 225-244, 1987.

15. Chai H, Farr RS, Froehlich LA, et al. Standardization of bronchial inhalation challenge procedures. J Allergy Clin Immunol 56: 323327, 1975.

16. Shykoff BE, Ploysongsang Y, Chang HK. Airflow and normal lung sounds. Am Rev Respir Dis 137: 872-876, 1988.

17. Nakano H, Sano K, Maekawa J, Narita N. Relationship between power spectra of breath sounds and inspiratory flows at different frequencies. Nihon Kyobu Shikkan Gakkai Zasshi 32: 1142-1148, 1994 (in Japanese, Abstract in English).

18. Yosef M, Langer R, Lev S, Glickman YA. Effect of airflow rate on vibration response imaging in normal lungs. Open Respir Med
J 3: 116-122, 2009.

19. Cavalcanti JV, Lopes AJ, Jansen JM, Melo PL. Detection of changes in respiratory mechanics due to increasing degrees of airway obstruction in asthma by the forced oscillation technique. Respir Med 100: 2207-2219, 2006.

20. Mori K, Shirai T, Mikamo M, et al. Colored 3-dimensional analyses of respiratory resistance and reactance in COPD and asthma. International Journal of COPD 8: 456-463, 2011.

The Internal Medicine is an Open Access journal distributed under the Creative Commons Attribution-NonCommercial-NoDerivatives 4.0 International License. To view the details of this license, please visit (https://creativecommons.org/licenses/ by-nc-nd/4.0/).

(C) 2019 The Japanese Society of Internal Medicine Intern Med 58: 47-52, 2019 